\title{
Effectiveness of a 12-month Exercise Intervention on Physical Activity and Quality of Life of Breast Cancer Survivors; Five-year Results of the BREX-study
}

\author{
HEIDI PENTTINEN ${ }^{1}$, MERI UTRIAINEN ${ }^{1}$, PIRKKO-LIISA KELLOKUMPU-LEHTINEN ${ }^{2}$, \\ JANI RAITANEN ${ }^{3,4}$, HARRI SIEVÄNEN ${ }^{3}$, RIKU NIKANDER ${ }^{3}$, \\ CARL BLOMQVIST $^{1}$, RIIKKA HUOVINEN ${ }^{5}$, LEENA VEHMANEN ${ }^{1}$ and TIINA SAARTO ${ }^{1}$ \\ ${ }^{1}$ Helsinki University Hospital, Comprehensive Cancer Center, and \\ Faculty of Medicine, University of Helsinki, Helsinki, Finland; \\ ${ }^{2}$ Department of Oncology, Tampere University Hospital and Faculty of Medicine and Life Sciences, \\ University of Tampere, Tampere, Finland; \\ ${ }^{3}$ UKK Institute for Health Promotion Research, Tampere, Finland; \\ ${ }^{4}$ Faculty of Social Sciences (Health Sciences), University of Tampere, Tampere, Finland; \\ ${ }^{5}$ Department of Oncology, Turku University Hospital and Faculty of Medicine, University of Turku, Turku, Finland
}

\begin{abstract}
Background/Aim: This is a report of the 5-year quality of life $(Q \circ L)$ findings of the BREX-study ( $n=444)$. Patients and Methods: A 12-month exercise intervention was arranged shortly after adjuvant treatments. Physical activity (PA) was assessed by PA diary, physical performance by a 2- km walking test, QoL by the EORTC QLQC30 and BR-23 questionnaires, fatigue by the FACIT-Fatigue scale and depression by the Beck's 13-item depression scale (BDI). Results: Participants who improved their PA from baseline to 5-year follow-up were more likely to improve their global health score $(R R R=1.02, p=0.016)$, physical $(R R R=1.02$, $p=0.009)$, social $(R R R=1.03, p=0.013)$, role functioning $(R R R=1.03, p=0.005)$, and fatigue $(R R R=1.02, p=0.002)$. An improved 2-km walking test was associated to improved global health, physical and role functioning, body image, future perspectives, and fatigue ( $p=0.011, p<0.001, p=0.001$, $p=0.021, p=0.012$ and $p=0.003$ ). No significant difference between the groups was found. Conclusion: Improvement in $P A$ or physical performance yields a positive change in $Q o L$ of breast cancer patients.
\end{abstract}

This article is freely accessible online.

Correspondence to: Heidi Penttinen, MD, Ph.D., Helsinki University Hospital, Comprehensive Cancer Center, and Faculty of Medicine, University of Helsinki, P.O. Box 180, 00029 HUS, Helsinki, Finland. Tel: +358 504287348, Fax: +358 947174247, e-mail: heidi.penttinen@fimnet.fi

Key Words: Breast cancer, exercise, rehabilitation, quality of life.
While breast cancer patients now live longer, the long-term adverse effects of adjuvant treatments and patients' QoL have become a more central issue. Physical activity (PA) is found to be a feasible, well tolerated and inexpensive way for addressing breast cancer survivors' physical and psychological issues (1-9). Physically active cancer survivors have significantly higher QoL than those who do not exercise $(10,11)$. Furthermore, a low PA correlates with poor physical health, depression symptoms, more severe fatigue and lower emotional health-related QoL $(12,13)$.

Despite the fact that physical exercise seems to have a positive impact on the physical and psychological well-being of cancer survivors, PA declines significantly after breast cancer diagnosis $(14,15)$ and increases only slowly after the treatment period (10). Therefore, an exercise intervention might provide an efficient approach to facilitate return to normal life. Although many survivors are motivated to make positive changes in their health behavior, exercise promotion may be needed to facilitate these changes $(16,17)$. In previous exercise studies, various interventions have been reported to improve QoL in breast cancer patients. However, most of the studies are small, their methodologies differ considerably, and the timing of the interventions has been variable - from interventions administered during adjuvant treatment for those delivered a few or even several years after the primary treatment (2, 4-9, 18-24). Among the large number of exercise intervention studies aiming at permanent changes of breast cancer patients' exercise behavior, only a few have reported results for more than two years' follow-up time (25-30). If exercise rehabilitation programs are to become an integral component of the multidisciplinary management of cancer 
survivors, large-scale randomized controlled trials and long follow-up periods after intervention would be useful to optimize their design.

We previously conducted a prospective randomized controlled BReast cancer and EXercise (BREX) trial where 500 Finnish women were randomized either to 12-month supervised exercise intervention or to control groups. We managed to recruit $78 \%$ of the eligible patients to BREX. With the exception of an age limit and musculoskeletal disorders, the study population represents the general Finnish breast cancer population (31). At baseline, due to the recently completed adjuvant treatment, the QoL of patients was impaired and their physical performance was poor compared with the general population (32). The previously published 12-month results of BREX did not indicate any effect of the exercise intervention on Qol, but showed a significant spontaneous recovery in both physical and mental condition $(33,34)$. Moreover, in both groups, increased PA was associated with improved QoL. In this paper, we report the QoL results of the BREX study five years from the baseline. The comparison is made between changes in QoL at baseline (before starting the intervention) and five years later. We also investigated the correlation between PA and physical performance, and Qol, fatigue and depression irrespective of study groups.

\section{Patients and Methods}

Patients. The BREX study was limited to include women aged 35-68 years who had recently (within four months) completed adjuvant chemotherapy or started the endocrine therapy of breast cancer. Detailed inclusion and exclusion criteria are presented in our previous publications $(31,33)$. The flow diagram is presented in Figure 1.

Ethical approval. All procedures performed in studies involving human participants were in accordance with the ethical standards of the institutional and/or national research committee and with the 1964 Helsinki declaration and its later amendments or comparable ethical standards. The BREX trial is registered in the Helsinki and Uusimaa Hospital District Clinical Trials Register (www.hus.fi) (trial number 210590) and at http://www.clinicaltrials.gov/ (identifier number NCT00639210).

Informed consent. Informed consent was obtained from all individual participants included in the study.

\footnotetext{
Methods

Intervention. This has been described in more detail in our previous publications (33). Shortly: The 1-year exercise intervention consisted of both supervised and home training. The 60-min supervised training was organized for the exercise group once a week with a rotating program of a step aerobics class and a circuit training class. The level of exercise was aimed at "somewhat hard" or "hard" (RPE 14-16). The home-based portion consisted of endurance training that was to be carried out at least twice a week. The control group was encouraged to maintain their normal level of physical activity and exercise habits throughout the study.
}

Table I. The background and medical characteristics (mean and standard deviation or frequency and proportion) at baseline for participants at a 5-year follow-up.

\begin{tabular}{|c|c|c|}
\hline & $\begin{array}{l}\text { Exercise } \\
\text { group }\end{array}$ & $\begin{array}{l}\text { Control } \\
\text { group }\end{array}$ \\
\hline $\mathrm{n}$ & 235 & 209 \\
\hline Age, mean (SD) & $52.8(7.2)$ & $53.3(7.7)$ \\
\hline \multicolumn{3}{|l|}{ Menopausal status (n, \%) } \\
\hline Premenopausal & $107(45.5)$ & $94(45.0)$ \\
\hline Postmenopausal & $128(54.5)$ & $115(55.0)$ \\
\hline \multicolumn{3}{|l|}{ BMI $(\mathrm{n}, \%)$} \\
\hline Normal $(<25)$ & $97(41.3)$ & $104(49.8)$ \\
\hline Overweight (25-29.9) & $93(39.6)$ & $77(36.8)$ \\
\hline Obese $(30+)$ & $45(19.1)$ & $28(13.4)$ \\
\hline Any reported disease $(\mathrm{n}, \%)$ & $125(53.2)$ & $112(53.6)$ \\
\hline Smokers (daily smoking) $(\mathrm{n}, \%)$ & $23(10.4)$ & $23(11.8)$ \\
\hline Education in years, mean (SD) & $14.1(3.5)$ & $13.9(3.3)$ \\
\hline The UKK 2-km walk test, mean (SD) & $18.2(2.1)$ & $17.9(1.8)$ \\
\hline \multicolumn{3}{|l|}{ Leisure-time physical activity } \\
\hline \multicolumn{3}{|l|}{ before cancer diagnosis $(\mathrm{n}, \%)$} \\
\hline Low & $44(20.2)$ & $29(15.1)$ \\
\hline Moderate & $117(53.7)$ & $118(61.5)$ \\
\hline High & $57(26.1)$ & $45(23.4)$ \\
\hline Tumor size $(\mathrm{mm})$, mean $(\mathrm{SD})$ & $21.6(12.8)$ & $23.6(15.2)$ \\
\hline Number of metastatic lymph nodes, mean (SD) & $1.9(2.8)$ & $1.8(3.6)$ \\
\hline Estrogen receptor-positive, mean (SD) & $199(84.7)$ & $168(80.4)$ \\
\hline Progesterone receptor-positive, mean (SD) & $158(67.2)$ & $141(67.5)$ \\
\hline \multicolumn{3}{|l|}{ Breast surgery, final $(\mathrm{n}, \%)$} \\
\hline Mastectomy & $110(46.8)$ & $112(53.6)$ \\
\hline Resection & $125(53.2)$ & $97(46.4)$ \\
\hline \multicolumn{3}{|l|}{ Axillary operation, final (n, \%) } \\
\hline Dissection & $167(71.1)$ & $154(73.7)$ \\
\hline Sentinel node biopsy & $68(28.9)$ & $55(26.3)$ \\
\hline Time since surgery (weeks), mean (SD) & $34.0(10.6)$ & $33.0(10.0)$ \\
\hline \multicolumn{3}{|l|}{ Adjuvant treatments (n, \%) } \\
\hline Chemotherapy & $209(88.9)$ & $192(91.9)$ \\
\hline Radiotherapy & $184(78.3)$ & $161(77.0)$ \\
\hline Endocrine treatment & $199(84.7)$ & $169(80.9)$ \\
\hline
\end{tabular}

The medical history of the patients was recorded at the BREX baseline visit after adjuvant treatments. In addition, the patients filled the questionnaires covering QoL, basic demographics and lifestyle issues. After the baseline visit and completion of the questionnaires, patients were randomized either into one-year supervised exercise training or to a control group. The questionnaires were repeated every six months for up to three years, then again five years from the baseline.

Physical activity. Physical activity was assessed by a prospective twoweek physical activity diary just before the start of the study and at follow-ups every six months until three years and then at the fiveyear follow-up. In the diary, activities were categorized as either being of light intensity, moderate, vigorous or very vigorous intensity ( $<3,3-6,6-9,>9$ on MET-h/wk scale, respectively), cf. (35).

Physical performance was tested immediately prior to the intervention and at one, three and five-year follow-ups by a 2-km walk test (UKK walk test, Tampere, Finland) (36). 


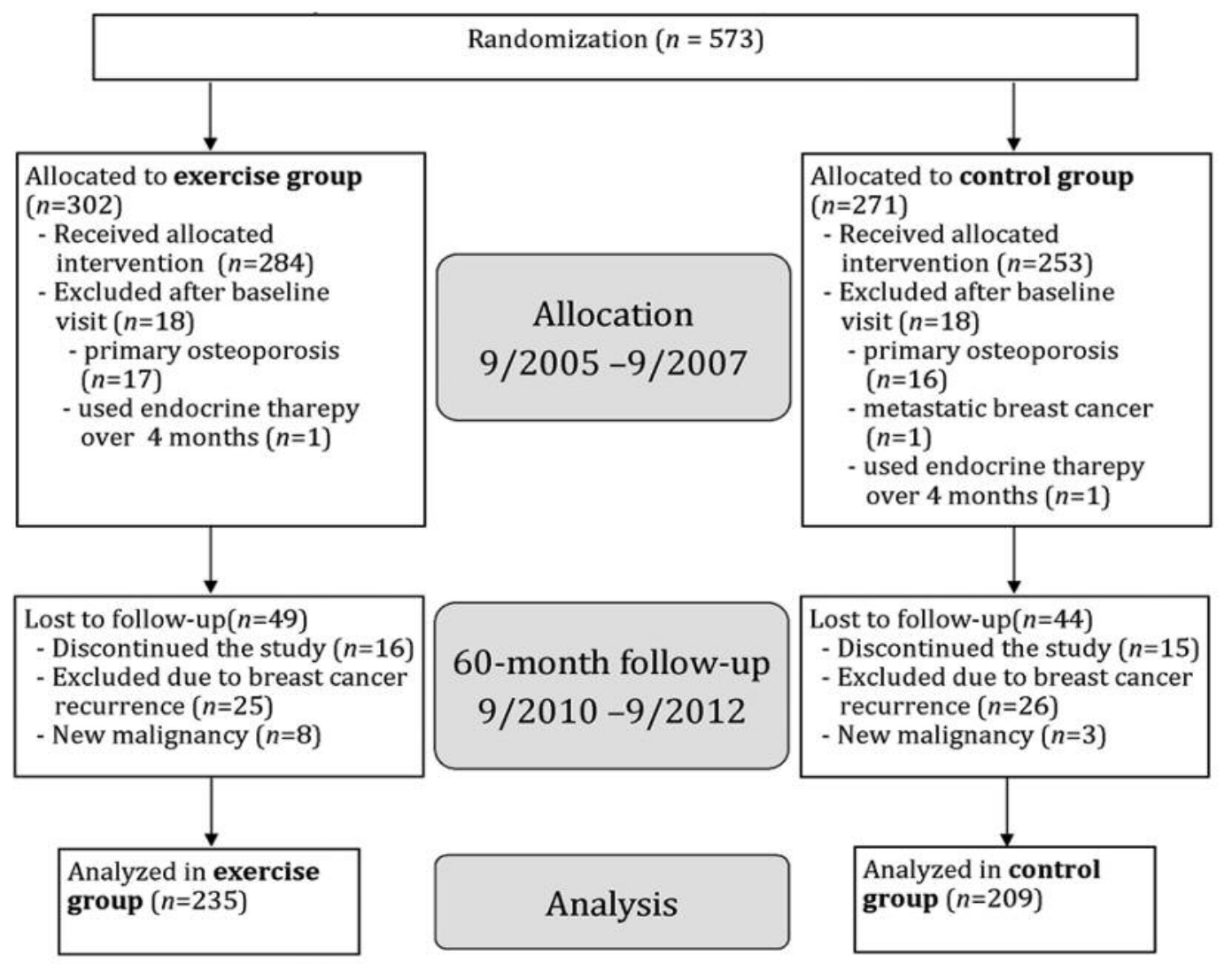

Figure 1. Flow chart.

Quality of life. Quality of life was measured by the EORTC QLQC30 (37) completed in conjunction with the breast cancer module of 23 questions (BR-23) (38). Symptoms of fatigue were assessed using the FACIT-Fatigue scale (39). Depressive symptoms were assessed by using the Finnish modified version of the Beck's 13-item depression scale (RBDI) (40). Patients answered the questionnaires at the baseline, at three, 12, 18, 24, 30, 36 and at 60 months respectively.

Statistical analysis. Depending on the particular variable, the background and medical characteristics of the patients were reported as means and standard deviations or frequencies and proportions. A multinomial logistic regression analysis was used to examine the association between study groups (independent variable) and changes in physical activity, QoL, fatigue, and depression (outcome variables). Changes in outcome variables from baseline to the 5-year follow-up were classified into three groups: physical activity and physical performance were classified based on tertiles (lowest tertile was used as a base category), and mental well-being variables were classified as a "negative change", "no change", and "positive change" where "negative change" was used as a base category. Changes were adjusted for baseline value of the particular outcome. All participants who completed two time points (baseline and 5-year follow-up) were included in these analyses, and therefore the sample size differed for each group. Statistical significance was set at $p<0.05$, and all analyses were performed with IBM SPSS Statistics 24.0.

\section{Results}

Patients' characteristics. The baseline characteristics of the patients who were included in the 5-year analysis $(n=444)$ are presented in Table I. The response rate to the QoL questionnaires in the 5-year follow-up was high, $83 \%$.

Between-group comparison. No significant differences between the groups in the changes of physical activity (PA) or physical performance were found during the five-year follow-up (Table II).

The associations between study groups and changes in QoL (EORTC-QLQ-C30), depression (RBDI) and fatigue (FACIT-F) measured from baseline to 5-year follow-up are shown in Table II. No significant differences between the groups were found, except in role functioning favoring the controls.

Association between changes in PA and physical performance and $Q o L$. All study participants irrespective of their study group were included in the secondary analyses of changes in PA and physical performance. Participants with increased physical activity measured by MET-h/wk were more likely to 
in vivo $33: 881-888(2019)$

Table II. Multinomial logistic regression models predicting changes in PA, QoL, fatigue, and depression by study group

\begin{tabular}{|c|c|c|c|c|c|}
\hline & \multirow[b]{2}{*}{$\mathrm{N}$} & \multicolumn{4}{|c|}{ From baseline to 5-year follow-up } \\
\hline & & No change RRR $(95 \% \mathrm{CI})$ & $p$-Value & Positive change RRR (95\%CI) & $p$-Value \\
\hline \multicolumn{6}{|l|}{ Physical activity } \\
\hline MetH & 372 & $1.12(0.65-1.95)$ & 0.69 & $0.86(0.51-1.45)$ & 0.56 \\
\hline UKK 2 to $\mathrm{km}$ walk test & 328 & $0.98(0.57-1.70)$ & 0.95 & $0.65(0.38-1.13)$ & 0.13 \\
\hline \multicolumn{6}{|l|}{ EORTC to QLQ to C30 } \\
\hline Global health score & 390 & $0.65(0.37-1.15)$ & 0.14 & $0.80(0.48-1.34)$ & 0.40 \\
\hline Physical functioning & 389 & $0.88(0.51-1.52)$ & 0.66 & $0.69(0.41-1.17)$ & 0.17 \\
\hline Social functioning & 389 & $0.58(0.28-1.21)$ & 0.15 & $0.52(0.21-1.28)$ & 0.16 \\
\hline Role functioning & 389 & $0.53(0.29-0.98)$ & 0.043 & $0.46(0.21-1.00)$ & 0.049 \\
\hline Emotional functioning & 391 & $1.25(0.75-2.09)$ & 0.40 & $1.07(0.63-1.81)$ & 0.81 \\
\hline Cognitive functioning & 391 & $1.05(0.61-1.82)$ & 0.86 & $0.86(0.45-1.65)$ & 0.65 \\
\hline \multicolumn{6}{|l|}{ EORTC to QLQ to BR23 } \\
\hline Body image & 383 & $0.82(0.42-1.59)$ & 0.55 & $1.31(0.72-2.39)$ & 0.38 \\
\hline Sexual functioning & 350 & $0.94(0.54-1.65)$ & 0.83 & $0.73(0.39-1.36)$ & 0.32 \\
\hline Sexual enjoyment & 133 & $0.69(0.28-1.69)$ & 0.42 & $0.73(0.22-2.41)$ & 0.61 \\
\hline Future perspective & 379 & $0.86(0.40-1.83)$ & 0.69 & $0.77(0.34-1.75)$ & 0.53 \\
\hline Systematic therapy & 386 & $1.06(0.63-1.79)$ & 0.82 & $0.89(0.50-1.59)$ & 0.70 \\
\hline Breast symptoms & 390 & $0.75(0.43-1.30)$ & 0.30 & $0.60(0.28-1.25)$ & 0.17 \\
\hline Arm symptoms & 390 & $0.97(0.57-1.64)$ & 0.90 & $0.56(0.31-1.02)$ & 0.060 \\
\hline FACIT to $\mathrm{F}$ & 370 & $2.49(0.95-6.54)$ & 0.065 & $1.05(0.66-1.67)$ & 0.85 \\
\hline RBDI & 149 & $1.17(0.48-2.85)$ & 0.73 & $0.61(0.26-1.43)$ & 0.25 \\
\hline
\end{tabular}

Adjusted for baseline value of the particular outcome. Negative change in depression and QoL as the base category and control group as a reference group. Relative risk ratios (RRR) with their $95 \%$ confidence intervals (CI) and $p$-values for the study group (RRR>1 in favor of the exercise group; RRR $<1$ in favor of the controls).

improve global health score $(\mathrm{RRR}=1.02, p=0.016)$, physical $(\mathrm{RRR}=1.02, p=0.009)$, social $(\mathrm{RRR}=1.03, p=0.013)$ and role functioning $(\mathrm{RRR}=1.03, p=0.005)$, and symptoms of fatigue $(\mathrm{RRR}=1.02, p=0.002)$ (Table III).

Participants with increased physical performance measured by the UKK 2-km walking test were more likely to improve global health score $(\mathrm{RRR}=1.33, p=0.011)$, physical $(\mathrm{RRR}=2.00, p \leq 0.001)$, and role functioning $(\mathrm{RRR}=1.79, \quad p=0.001)$, the body image $(\mathrm{RRR}=1.33$, $p=0.021)$ and the future perspective $(\mathrm{RRR}=1.49, p=0.012)$ scales of the EORTC-QLQ-BR23, and also symptoms of fatigue $(\mathrm{RRR}=1.35, p=0.003)$ (Table IV).

\section{Discussion}

In the present study, for the first time to our knowledge, we demonstrated a long-term positive association between both improved PA and QoL and objectively measured improved physical performance and QoL of breast cancer survivors after adjuvant treatments. While there were no significant differences between the study groups, we found clear associations between changes in both PA and physical performance, and different dimensions of QoL.

There is accumulating evidence for the potential of exercise interventions to be an effective and cost-efficient approach to facilitate breast cancer survivors' return to normal life. In previous exercise studies, various interventions have been reported improving QoL in breast cancer patients $(2,4-9,18-24)$. Timing health promotion interventions to the rehabilitation period, i.e., the period after active adjuvant treatment, as in the present study, is seen as particularly promising, as it targets the possibly challenging transition from life-as-patient, with all its medical and social support related to the treatment, to normal life (41-43).

In addition to the present study, there have been only two RCT to examine the long-term (5 years or more) effects of an exercise intervention in breast cancer survivors $(29,30)$ and a few studies with 2-year follow-up (25-28), however not with the same QoL endpoints as in our study.

Sagen et al. tested a 6-month physical activity program to reduce lymphoedema after breast cancer surgery. They did not find any difference in arm volume or lymphoedema between the study groups. Quality of life was not studied. There was a $27 \%$ dropout rate in the two-year follow-up (25).

Hayes et al. evaluated the effects of an 8-month pragmatic exercise intervention on disease-free survival (DFS) and overall survival (OS) of participants. The intervention was delivered face-to-face or by telephone commencing six weeks after breast surgery. Patients were randomized to exercise group $(n=207)$ or to usual care $(n=130)$. After a median follow-up of 8.3 years the hazard ratio (HR) for OS in the intervention group compared with usual care was 0.45 ; 
Table III. Multinomial logistic regression models predicting changes in QoL, fatigue, and depression (negative change as the base category) by change in physical activity (MET-h/wk).

\begin{tabular}{|c|c|c|c|c|c|}
\hline & \multirow[b]{2}{*}{$\mathrm{N}$} & \multicolumn{4}{|c|}{ From baseline to 5-year follow-up } \\
\hline & & No change RRR (95\%CI) & $p$-Value & Positive change RRR (95\%CI) & $p$-Value \\
\hline \multicolumn{6}{|l|}{ EORTC-QLQ-C30 } \\
\hline Global health score & 358 & $1.02(1.00-1.03)$ & 0.057 & $1.02(1.00-1.03)$ & 0.016 \\
\hline Physical functioning & 357 & $1.01(1.00-1.03)$ & 0.12 & $1.02(1.01-1.04)$ & 0.009 \\
\hline Social functioning & 358 & $1.01(0.99-1.03)$ & 0.38 & $1.03(1.01-1.06)$ & 0.013 \\
\hline Role functioning & 357 & $1.03(1.01-1.05)$ & 0.001 & $1.03(1.01-1.06)$ & 0.005 \\
\hline Emotional functioning & 359 & $1.01(0.99-1.02)$ & 0.33 & $1.00(0.99-1.02)$ & 0.76 \\
\hline Cognitive functioning & 359 & $1.01(0.99-1.02)$ & 0.29 & $1.01(1.00-1.03)$ & 0.13 \\
\hline \multicolumn{6}{|l|}{ EORTC-QLQ-BR23 } \\
\hline Body image & 352 & $1.00(0.99-1.02)$ & 0.91 & $1.00(0.98-1.01)$ & 0.88 \\
\hline Sexual functioning & 322 & $1.01(1.00-1.03)$ & 0.086 & $1.01(1.00-1.03)$ & 0.098 \\
\hline Sexual enjoyment & 122 & $1.00(0.98-1.03)$ & 0.74 & $1.03(1.00-1.06)$ & 0.060 \\
\hline Future perspective & 349 & $1.01(0.99-1.03)$ & 0.37 & $1.01(0.98-1.03)$ & 0.61 \\
\hline Systematic therapy & 355 & $1.00(0.98-1.01)$ & 0.75 & $1.01(0.99-1.02)$ & 0.28 \\
\hline Breast symptoms & 358 & $1.00(0.99-1.01)$ & 0.96 & $1.00(0.98-1.02)$ & 0.78 \\
\hline Arm symptoms & 358 & $1.00(0.98-1.01)$ & 0.52 & $1.01(1.00-1.03)$ & 0.096 \\
\hline FACIT-F & 343 & $1.01(0.99-1.04)$ & 0.31 & $1.02(1.01-1.04)$ & 0.002 \\
\hline RBDI & 141 & $0.99(0.97-1.01)$ & 0.43 & $1.00(0.98-1.02)$ & 0.77 \\
\hline
\end{tabular}

Relative risk ratios (RRR) with their $95 \%$ confidence intervals (CI) and $p$-values for a change in MET-H/wk (RRR $>1$ in favor of improved physical activity, RRR $<1$ in favor of decreased physical activity).

there was no difference in DFS between the groups (HR=0.66). While not establishing causality, Hayes et al. suggest the potential of physical activity to improve survival. In the study of Hayes et al. there were only 11 (5.3\%) deaths in the exercise group compared with $15(11.5 \%)$ deaths in the usual care group during 8.3 years follow-up time. So far, the study of Hayes is the only randomized controlled exercise trial that has reported DFS (30).

Within the BREX study, we shall later report DFS and OS in our ten-year follow-up analysis. Previously, a large cohort study $(n=2,987)$ showed that physically active breast cancer patients have half the risk of recurrence and death compared with sedentary women (44).

In a study by Mutrie et al., 203 women participated in a 12week supervised group exercise program during treatment for early stage breast cancer. The intervention consisted of a variety of cardiovascular, muscular strength, and flexibility exercises, also including group discussions on techniques aiming at change in exercise behavior. The control group received usual care until the 6-month follow-up, at which point they had discussions about healthy lifestyle. The results showed a significant intervention effect at 12 weeks and 6 months followup for meters walked in $12 \mathrm{~min}$, minutes of moderate intensity activity reported in a week, shoulder mobility, breast cancer specific subscale of quality of life and for positive mood. However, no significant effect of the exercise intervention was found in global Qol. Mutrie et al. later contacted those 148 study patients who had agreed to being contacted again and invited them to participate in a further follow-up. Attendance rate to follow-up in 18 months was 114 women and in 60 months only 87 women (out of 203). The women in the original intervention group reported more physical activity and more positive mood at the 60 months follow-up than the women in the original control group (29).

The study of Mutrie et al., however, differed from BREX as to the study population, the duration of the intervention and the follow-up program. In BREX, $80-85 \%$ of the patients exercised regularly before their diagnosis, whereas Mutrie et al. excluded women with regular exercise habits and only recruited sedentary patients. This might also explain the difference in dropouts. In BREX, there were only $17 \%$ dropouts in five years, whereas in Mutrie's study the proportion of dropouts was $58 \%$. During five years in BREX, only 31 patients out of 538 (5.8\%) discontinued the study on their own accord, which reflects a high level of motivation even in control group patients.

In line with the BREX findings, however, in Mutrie's study, irrespective of original group allocation, women who were more active consistently reported lower levels of depression and increased quality of life compared with those who were less active (29). Similarly, in the present study, physical activity was positively associated with QoL independently of the intervention group, especially with the physical, social and role functions and with (lack of) symptoms of fatigue. Improved physical performance was also positively associated to QoL, fatigue and body image, 
Table IV. Multinomial logistic regression models predicting changes in QoL, fatigue, and depression (negative change as the base category) by change in physical performance (the UKK 2-km walk test).

\begin{tabular}{|c|c|c|c|c|c|}
\hline & \multirow[b]{2}{*}{$\mathrm{N}$} & \multicolumn{4}{|c|}{ From baseline to 5-year follow-up } \\
\hline & & No change RRR (95\%CI) & $p$-Value & Positive change RRR (95\%CI) & $p$-Value \\
\hline \multicolumn{6}{|l|}{ EORTC-QLQ-C30 } \\
\hline Global health score & 303 & $1.03(0.83-1.28)$ & 0.77 & $1.33(1.08-1.67)$ & 0.011 \\
\hline Physical functioning & 302 & $1.61(1.25-2.08)$ & $<0.001$ & $2.00(1.54-2.63)$ & $<0.001$ \\
\hline Social functioning & 303 & $0.75(0.54-1.04)$ & 0.090 & $0.83(0.54-1.28)$ & 0.41 \\
\hline Role functioning & 302 & $1.18(0.93-1.52)$ & 0.18 & $1.79(1.27-2.56)$ & 0.001 \\
\hline Emotional functioning & 304 & $1.15(0.93-1.41)$ & 0.19 & $1.15(0.93-1.43)$ & 0.19 \\
\hline Cognitive functioning & 304 & $1.06(0.85-1.33)$ & 0.57 & $1.18(0.89-1.56)$ & 0.24 \\
\hline \multicolumn{6}{|l|}{ EORTC-QLQ-BR23 } \\
\hline Body image & 299 & $1.45(1.10-1.92)$ & 0.008 & $1.33(1.04-1.69)$ & 0.021 \\
\hline Sexual functioning & 272 & $0.99(0.78-1.27)$ & 0.93 & $1.15(0.88-1.49)$ & 0.31 \\
\hline Sexual enjoyment & 103 & $0.87(0.58-1.30)$ & 0.48 & $1.27(0.74-2.17)$ & 0.39 \\
\hline Future perspective & 297 & $1.23(0.95-1.61)$ & 0.11 & $1.49(1.09-2.00)$ & 0.012 \\
\hline Systematic therapy & 301 & $1.11(0.89-1.37)$ & 0.35 & $1.20(0.94-1.52)$ & 0.14 \\
\hline Breast symptoms & 303 & $0.92(0.72-1.18)$ & 0.52 & $1.20(0.89-1.62)$ & 0.22 \\
\hline Arm symptoms & 303 & $1.32(1.06-1.65)$ & 0.013 & $1.17(0.91-1.51)$ & 0.22 \\
\hline FACIT-F & 291 & $1.45(0.98-2.13)$ & 0.066 & $1.35(1.10-1.67)$ & 0.003 \\
\hline RBDI & 119 & $1.09(0.72-1.61)$ & 0.70 & $0.85(0.56-1.30)$ & 0.46 \\
\hline
\end{tabular}

Relative risk ratios (RRR) with their 95\% confidence intervals (CI) and $p$-values for a change in the UKK 2-km walk test time (RRR $>1$ in favor of improved physical performance, $\mathrm{RRR}<1$ in favor of decreased physical performance).

and, in addition, to future perspective. This last finding suggests that improved physical performance can be an empowering factor for women who have survived cancer and are struggling to return to their normal life.

In this context, it is necessary to critically address the concept of intervention. In BREX, as in any similar study testing a behavioral intervention, it is impossible to have a double-blind design. The patients will, of course, know whether or not they are included in free regular exercise. In addition, to get informed consent, they all have learned about the aims of the study and about the underlying hypothesis that physical exercise would improve their quality of life. Indeed, the initial information regarding the supposed beneficial effects of exercise can be seen as to constitute a motivational mini-intervention of its own. In addition, the control group participated in the same controls and tests as the study group. The tests also covered their exercise behavior and physical performance. Thereby they were throughout the study period repeatedly reminded of the importance of exercise.

Follow-up of a specific group is a powerful intervention per se. In classic psychology literature (albeit mostly applied in organizational settings) this is known as the Hawthorne effect. Groups that are subject to special attention tend to ameliorate their results independently of how beneficial in fact the interventions they are subjected to are. It is reasonable to believe that the PA levels of the control group would have been lower without the initial motivational intervention and the thematic follow-up.
In fact, the BREX study can be seen, as a whole, consisting of three intervention modules: initial information regarding exercise and QoL, a thematic follow-up program, and a free weekly 1-year exercise program. Of these three, the control group was only excluded from the free exercise module. Therefore, it is no great surprise that there are practically no differences between the groups. The interesting finding is that, through whatever means it is achieved, an increase in PA in breast cancer survivors is, even in a 5-year follow-up, associated with a higher quality of life.

\section{Conclusion}

During the 5-year follow-up there was no significant impact of the 12-month exercise intervention on QoL, compared to the control group. Given the strong association between PA and QoL, however, it seems that supporting a life style with regular exercise can be a powerful method of helping breast cancer survivors to achieve better quality of life when returning to their life-after-illness. Our findings suggest that this might be achieved by integrating a follow-up of exercise behavior and of physical performance into the normal clinical follow-up procedure.

\section{Funding}

This study was funded by the Finnish Cancer Institute (grant numbers 7210 and 7325), the Finnish Cancer Foundation (7369), the Finnish Academy (609), the Social Insurance Institution of 
Finland (2898), The Finnish Ministry of Education (7387), Finska Läkaresällskapet (7388), the Special Government Grant for Health Science Research, the Pirkanmaa Research Foundation, the Helander Foundation (7370), the Gyllenberg Foundation (7371), the Paulo Foundation and the Kurt and Doris Palander Foundation and Helsinki University Hospital, Comprehensive Cancer Center. The study is sponsored by the Finnish Breast Cancer group (7340).

\section{Conflicts of Interest}

The Authors declare that they have no conflict of interest.

\section{Authors' Contributions}

Study design: TS (principal investigator), CB (principal investigator), PK-L (Tampere centre principal investigator), RH (Turku centre principal investigator), HS (physical exercise intervention plan) and RN (physical exercise intervention plan). Patient recruitment, follow-up and data collection: HP, LV, MU, PK-L, RH, RN. Data analysis: JR, CB, TS, HP. Written report: HP, MU, LV, TS, CB. All Authors commented on and approved the final manuscript. HP takes responsibility of the whole manuscript.

\section{Acknowledgements}

The Authors thank the study nurses Nina Puolakka, Leena Kaartinen, Outi Malkavaara and Kirsi-Maria Rintala for their great effort. The Authors are greatly indebted to Professor Liisa Hakamies-Blomqvist for her useful comments.

\section{References}

1 Markes M, Brockow T and Resch KL: Exercise for women receiving adjuvant therapy for breast cancer. Cochrane Database Syst Rev 4: CD005001, 2006. PMID: 17054230. DOI: 10.1002/ 14651858.CD005001.pub2

2 McNeely ML, Campbell KL, Rowe BH, Klassen TP, Mackey JR and Courneya KS: Effects of exercise on breast cancer patients and survivors: a systematic review and meta-analysis. CMAJ 175: 34-41, 2006. PMID: 16818906. DOI: 10.1503/cmaj.051073

3 Kim CJ, Kang DH and Park JW: A meta-analysis of aerobic exercise interventions for women with breast cancer. West $\mathrm{J}$ Nurs Res 31: 437-461, 2009. PMID: 19176403. DOI: 10.1177/ 0193945908328473

4 White SM, McAuley E, Estabrooks PA and Courneya KS: Translating physical activity interventions for breast cancer survivors into practice: an evaluation of randomized controlled trials. Ann Behav Med 37: 10-19, 2009. PMID: 19255819. DOI: 10.1007/s12160-009-9084-9

5 Bicego D, Brown K, Ruddick M, Storey D, Wong C and Harris SR: Effects of exercise on quality of life in women living with breast cancer: a systematic review. Breast J 15: 45-51, 2009. PMID: 19120381. DOI: 10.1111/j.1524-4741.2008.00670.

6 Schmitz KH and Speck RM: Risks and benefits of physical activity among breast cancer survivors who have completed treatment. Womens Health (Lond Engl) 6: 221-238, 2010. PMID: 20187728. DOI: 10.2217/whe.10.1
7 Duijts SF, Faber MM, Oldenburg HS, van Beurden $M$ and Aaronson NK: Effectiveness of behavioral techniques and physical exercise on psychosocial functioning and health-related quality of life in breast cancer patients and survivors--a meta-analysis. Psychooncology 20: 115-126, 2011. PMID: 20336645. DOI: 10.1002/pon. 1728

8 Ferrer RA, Huedo-Medina TB, Johnson BT, Ryan S and Pescatello LS: Exercise interventions for cancer survivors: a metaanalysis of quality of life outcomes. Ann Behav Med 41: 32-47, 2011. PMID: 20931309. DOI: 10.1007/s12160-010-9225-1

9 Fong DY, Ho JW, Hui BP, Lee AM, Macfarlane DJ and Leung SS, Cerin E, Chan WY, Leung IP, Lam SH, Taylor AJ and Cheng KK: Physical activity for cancer survivors: meta-analysis of randomised controlled trials. BMJ 344: e70, 2012. PMID: 22294757. DOI: 10.1136/bmj.e70

10 Courneya KS and Friedenreich CM: Relationship between exercise pattern across the cancer experience and current quality of life in colorectal cancer survivors. J Altern Complement Med Fall 3: 215226, 1997. PMID: 9430325. DOI: 10.1089/acm.1997.3.215

11 Young-McCaughan $\mathrm{S}$ and Sexton DL: A retrospective investigation of the relationship between aerobic exercise and quality of life in women with breast cancer. Oncol Nurs Forum 18: 751-757, 1991. PMID: 2067964.

12 Servaes P, Verhagen S and Bleijenberg G: Determinants of chronic fatigue in disease-free breast cancer patients: a crosssectional study. Ann Oncol 13: 589-598, 2002. PMID: 12056710.

13 Emery CF, Yang HC, Frierson GM, Peterson LJ and Suh S: Determinants of physical activity among women treated for breast cancer in a 5-year longitudinal follow-up investigation. Psychooncology 18: 377-386, 2009. PMID: 19241490. DOI: 10.1002/pon.1519

14 Irwin ML, Crumley D, McTiernan A, Bernstein L, Baumgartner R, Gilliland FD, Kriska A and Ballard-Barbash R: Physical activity levels before and after a diagnosis of breast carcinoma: The Health, Eating, Activity, and Lifestyle (HEAL) study. Cancer 1: 1746-1757, 2003. PMID: 12655532. DOI: 10.1002/cncr.11227

15 Irwin ML and Ainsworth BE: Physical activity interventions following cancer diagnosis: methodologic challenges to delivery and assessment. Cancer Invest 22: 30-50, 2004. PMID: 15069762.

16 Gjerset GM, Fossa SD, Courneya KS, Skovlund E, Jacobsen AB and Thorsen L: Interest and preferences for exercise counselling and programming among Norwegian cancer survivors. Eur J Cancer Care (Engl) 20: 96-105, 2011. PMID: 20345456. DOI: 10.1111/j.1365-2354.2009.01161.x

17 Alfano CM, Day JM, Katz ML, Herndon JE, 2nd, Bittoni MA, Oliveri JM, Donohue K and Paskett ED: Exercise and dietary change after diagnosis and cancer-related symptoms in long-term survivors of breast cancer: CALGB 79804. Psychooncology 18 : 128-133, 2009. PMID: 18536022. DOI: 10.1002/pon.1378

18 Jones LW and Demark-Wahnefried W: Diet, exercise, and complementary therapies after primary treatment for cancer. Lancet Oncol 7: 1017-1026, 2006. PMID: 17138223. DOI: 10.1016/S14702045(06)70976-7

19 Kirshbaum MN: A review of the benefits of whole body exercise during and after treatment for breast cancer. J Clin Nurs 16: 104121, 2007. PMID: 17181672. DOI: 10.1111/j.1365-2702.2006. 01638.x

20 Demark-Wahnefried W and Jones LW: Promoting a healthy lifestyle among cancer survivors. Hematol Oncol Clin North Am 22: 319342, 2008. PMID: 18395153. DOI: 10.1016/j.hoc.2008.01.012 
21 Spence RR, Heesch KC and Brown WJ: Exercise and cancer rehabilitation: a systematic review. Cancer Treat Rev 36: 185-194, 2010. PMID: 19962830. DOI: 10.1016/j.ctrv.2009.11.003

22 Battaglini CL, Mills RC, Phillips BL, Lee JT, Story CE, Nascimento MG and Hackney AC: Twenty-five years of research on the effects of exercise training in breast cancer survivors: A systematic review of the literature. World J Clin Oncol 5: 177190, 2014. PMID: 24829866. DOI: 10.5306/wjco.v5.i2.177

23 Singh B, Spence RR, Steele ML, Sandler CX, Peake JM and Hayes SC: A systematic review and meta-analysis of the safety, feasibility and effect of exercise in women with stage II+ breast cancer. Arch Phys Med Rehabil 99: 2621-2636, 2018. PMID: 29730319. DOI: 10.1016/j.apmr.2018.03.026

24 Zhang X, Li Y and Liu D: Effects of exercise on the quality of life in breast cancer patients: a systematic review of randomized controlled trials. Support Care Cancer 27: 9-21, 2018. PMID: 30032399. DOI: 10.1007/s00520-018-4363-2

25 Sagen A, Karesen R and Risberg MA: Physical activity for the affected limb and arm lymphedema after breast cancer surgery. A prospective, randomized controlled trial with two years follow-up. Acta Oncol 48: 1102-1110, 2009. PMID: 19863217. DOI: $10.3109 / 02841860903061683$

26 Demark-Wahnefried W, Colditz GA, Rock CL, Sedjo RL, Liu J, Wolin KY, Krontiras H, Byers T, Pakiz B, Parker BA, Naughton M, Elias A, Ganz PA and ENERGY Trial Group: Quality of life outcomes from the exercise and nutrition enhance recovery and good health for you (ENERGY)-randomized weight loss trial among breast cancer survivors. Breast Cancer Res Treat 154: 329337, 2015. PMID: 26518022. DOI: 10.1007/s10549-015-3627-5

27 Rock CL, Flatt SW, Byers TE, Colditz GA, Demark-Wahnefried W, Ganz PA, Wolin KY, Elias A, Krontiras H, Liu J, Naughton M, Pakiz B, Parker BA, Sedjo RL and Wyatt H: Results of the exercise and nutrition to enhance recovery and good health for you (ENERGY) trial: A behavioral weight loss intervention in overweight or obese breast cancer survivors. J Clin Oncol 33: 31693176, 2015. PMID: 26282657. DOI: 10.1200/JCO. 2015.61.1095

28 Goodwin PJ, Segal RJ, Vallis M, Ligibel JA, Pond GR, Robidoux A, Blackburn GL, Findlay B, Gralow JR, Mukherjee S, Levine M and Pritchard KI: Randomized trial of a telephone-based weight loss intervention in postmenopausal women with breast cancer receiving letrozole: The LISA trial. J Clin Oncol 32: 2231-2239, 2014. PMID: 24934783. DOI: 10.1200/JCO.2013.53.1517

29 Mutrie N, Campbell A, Barry S, Hefferon K, McConnachie A, Ritchie D and Tovey S: Five-year follow-up of participants in a randomised controlled trial showing benefits from exercise for breast cancer survivors during adjuvant treatment. Are there lasting effects? J Cancer Surviv 6: 420-430, 2012. PMID: 22836201. DOI: $10.1007 / \mathrm{s} 11764-012-0233-y$

30 Hayes S, Steele M and Spence R: Can exercise influence survival following breast cancer: Results from a randomised, controlled trial. J Clin Oncol 35: 10067-10067, 2017.

31 Penttinen H, Nikander R, Blomqvist C, Luoto R and Saarto T: Recruitment of breast cancer survivors into a 12-month supervised exercise intervention is feasible. Contemp Clin Trials 30: 457-463, 2009. PMID: 19394448. DOI: 10.1016/j.cct.2009.04.007

32 Penttinen HM, Saarto T, Kellokumpu-Lehtinen P, Blomqvist C, Huovinen R, Kautiainen H, Järvenpää S, Nikander R, Idman I, Luoto R, Sievänen $H$, Utriainen $M$, Vehmanen L, Jääskeläinen AS, Elme A, Ruohola J, Luoma M and Hakamies-Blomqvist L: Quality of life and physical performance and activity of breast cancer patients after adjuvant treatments. Psychooncology 20: 1211-1220, 2011. PMID: 20878646. DOI: 10.1002/pon.1837

33 Saarto T, Penttinen HM, Sievanen H, Kellokumpu-Lehtinen PL, Hakamies-Blomqvist L, Nikander R, Huovinen R, Luoto R, Kautiainen H, Järvenpää S, Idman I, Utriainen M, Vehmanen L, Jääskeläinen AS, Elme A, Ruohola J, Palva T, Vertio H, Rautalahti M, Fogelholm M, Blomqvist $\mathrm{C}$ and Luoma ML: Effectiveness of a 12-month exercise program on physical performance and quality of life of breast cancer survivors. Anticancer Res 32: 3875-3884, 2012. PMID: 22993332.

34 Penttinen H, Rautalin M, Roine R, Jahkola T, KellokumpuLehtinen PL, Huovinen R, Kautiainen $H$, Järvenpää $S$, Hakamies-Blomqvist L, Blomqvist C and Saarto T: Quality of life of recently treated patients with breast cancer. Anticancer Res 34: 1201-1206, 2014. PMID: 24596360.

35 Baranowski T, Smith M, Thompson WO, Baranowski J, Hebert $\mathrm{D}$ and de Moor $\mathrm{C}$ : Intraindividual variability and reliability in a 7-day exercise record. Med Sci Sports Exerc 31: 1619-1622, 1999. PMID: 10589866.

36 Oja P, Laukkanen R, Pasanen M, Tyry T and Vuori I: A 2-km walking test for assessing the cardiorespiratory fitness of healthy adults. Int J Sports Med 12: 356-362, 1991. PMID: 1917218. DOI: $10.1055 / \mathrm{s}-2007-1024694$.

37 Aaronson NK, Ahmedzai S, Bergman B, Bullinger M, Cull A, Duez NJ, Filiberti A, Flechtner H, Fleishman SB and de Haes JC: The European Organization for Research and Treatment of Cancer QLQ-C30: A quality-of-life instrument for use in international clinical trials in oncology. J Natl Cancer Inst 85: 365-376, 1993. PMID: 8433390.

38 Sprangers MA, Groenvold M, Arraras JI, Franklin J, te Velde A, Muller M, Franzini L, Williams A, de Haes HC, Hopwood P, Cull A and Aaronson NK: The European Organization for Research and Treatment of Cancer breast cancer-specific qualityof-life questionnaire module: First results from a three-country field study. J Clin Oncol 14: 2756-2768, 1996. PMID: 8874337, DOI: $10.1200 / J C O .1996 .14 .10 .2756$

39 Van Belle S, Paridaens R, Evers G, Kerger J, Bron D, Foubert J, Ponnet G, Vander Steichel D, Heremans C and Rosillon D: Comparison of proposed diagnostic criteria with FACT-F and VAS for cancer-related fatigue: Proposal for use as a screening tool. Support Care Cancer 13: 246-254, 2005. PMID: 15549424, DOI: 10.1007/s00520-004-0734-y

40 Beck AT, Rial WY and Rickels K: Short form of depression inventory: Cross-validation. Psychol Rep 34: 1184-1186, 1974. PMID: 4424377.

41 Ward SE, Viergutz G, Tormey D, deMuth J and Paulen A: Patients' reactions to completion of adjuvant breast cancer therapy. Nurs Res 41: 362-366, 1992. PMID: 1437586.

42 McKinley ED: Under Toad days: Surviving the uncertainty of cancer recurrence. Ann Intern Med 133: 479-480, 2000. PMID: 10975969.

43 Schnipper HH: Life after breast cancer. J Clin Oncol 19: 3581-3584, 2001. PMID: 11481368. DOI: 10.1200/JCO.2001. 19.15.3581

44 Holmes MD, Chen WY, Feskanich D, Kroenke CH and Colditz GA: Physical activity and survival after breast cancer diagnosis. JAMA 293: 2479-2486, 2005. PMID: 15914748. DOI: 10.1001/jama.293.20.2479

Received February 5, 2019

Revised February 28, 2019 Accepted March 5, 2019 